\title{
CNC Technology in Wood Surface Processing
}

\section{HORMAN, I.; AZEMOVIC, E. \& PANDZO, A.}

Abstract: This final paper analyzes two lines, manual application (hereinafter L1) and automatic application (hereinafter L2), where the shortcomings of the L1 line were identified and after that the technological line L2 was proposed, which was improved by CNC technology. The introductory part generally refers to the surface treatment of wood. A brief overview of the history and development of wood surface treatment is given. Basic concepts are explained, such as wetting and spilling of liquid materials, film adhesion, internal stresses, technological process, surface treatment lines with numerical control and technological lacquer line, manual application. In the central part of the paper, a detailed description of the technological painting line L1-manual application and a description of the technological painting line L2-automatic application are given. The ancillary equipment used on both lines is described, as well as the material used.After the analysis of the lacquer line L1 and line L2, the test methodology is described: measurements and testing of basic properties of coating materials, testing of liquid materials, dry matter content and volatile constituents, amount of varnish application on the surface and thickness of dry films. In the last part, testing for both painting lines L1 and L2, display and discussion of the results were performed. Demonstrated from the obtained results that the application of CNC technology increases the production capacity and precision of production, reduces the number of scrap pieces, and achieves better quality of the final product. The results of this research have shown that by using CNC technology we have a justified investment for the production of high quality furniture.

Key words: List 4-5 keywords. (14 pt, italic, 5 words max, separate by commas)
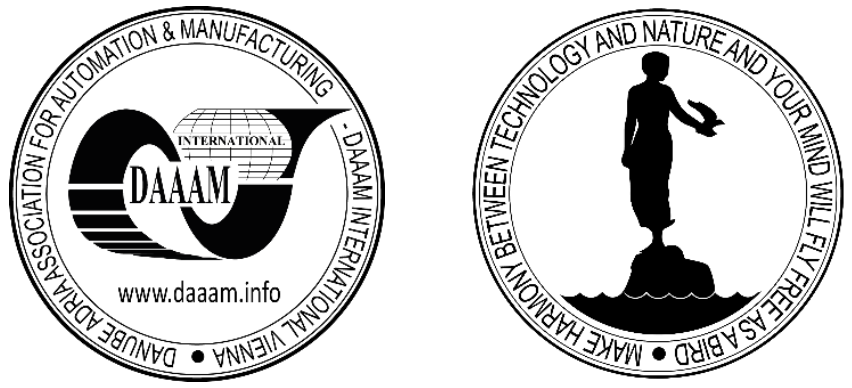

Authors' data: Univ.Prof.dr. Izet Horman, Mr.Sc. Esed Azemovic dip.mech.eng*; Mag.Sc. Amina Pandžo mech.eng**, * Faculty of Mechanical Engineering, Sarajevo **Vilsonovo šetalište 9. 71000 Sarajevo Bosnia and Herzegovina, horman@mef.uns.ba, amina.pandzo@ hotmail.com,esed@saplast.ba

This Publication has to be referred as: Horman, I[zet]; Azemovic, E[sed] \& Pandzo, A[mina] (2020). CNC Technology in Wood Surface Processing, Chapter 11 in DAAAM International Scientific Book 2020, pp.143-150, B. Katalinic (Ed.), Published by DAAAM International, ISBN 978-3-902734-27-3, ISSN 1726-9687, Vienna, Austria

DOI: 10.2507/daaam.scibook.2020.11 
Horman, I.; Azemovic, E. \& Pandzo, A.: CNC Technology in Wood Surface Proce...

\section{Introduction}

Quality of product is the key aspect of any modern and organized production. In production practice, it is important to establish optimal ratio between quality, economy of production as well as delivery time. Product quality can be defined trough production quality and quality reliability in exploitation. System quality insurance is compatible with ISO 9000 or other certifitactes, which are follow by others european standards, demends from manufacturer production of product which are verified trough strenght test. In case of wood surface processing, that is reflected trough the quality of the applied film and it's surface strength, quality, the wood look and surface protection from outside agens. For wood surface processing in this work, UV water varnish and water varnish are being used.

\section{Materials and methods}

In last couple years, during production and application for wood surface processing, there has been a lot of improvement.Greater intention is focused towards the system that are preventing environment pollution, require less energy and produce more quality film. In that case, great research efforts are being made for wood surface processing, which include the manufacturer of material for surface processing as well as technology supplier and material user.

Methods used in this paper work are as follows:

- manual spraying (airless dispersion), used with water varnish L-1

- electron spraying used for UV water varnish with the help of robot hand.

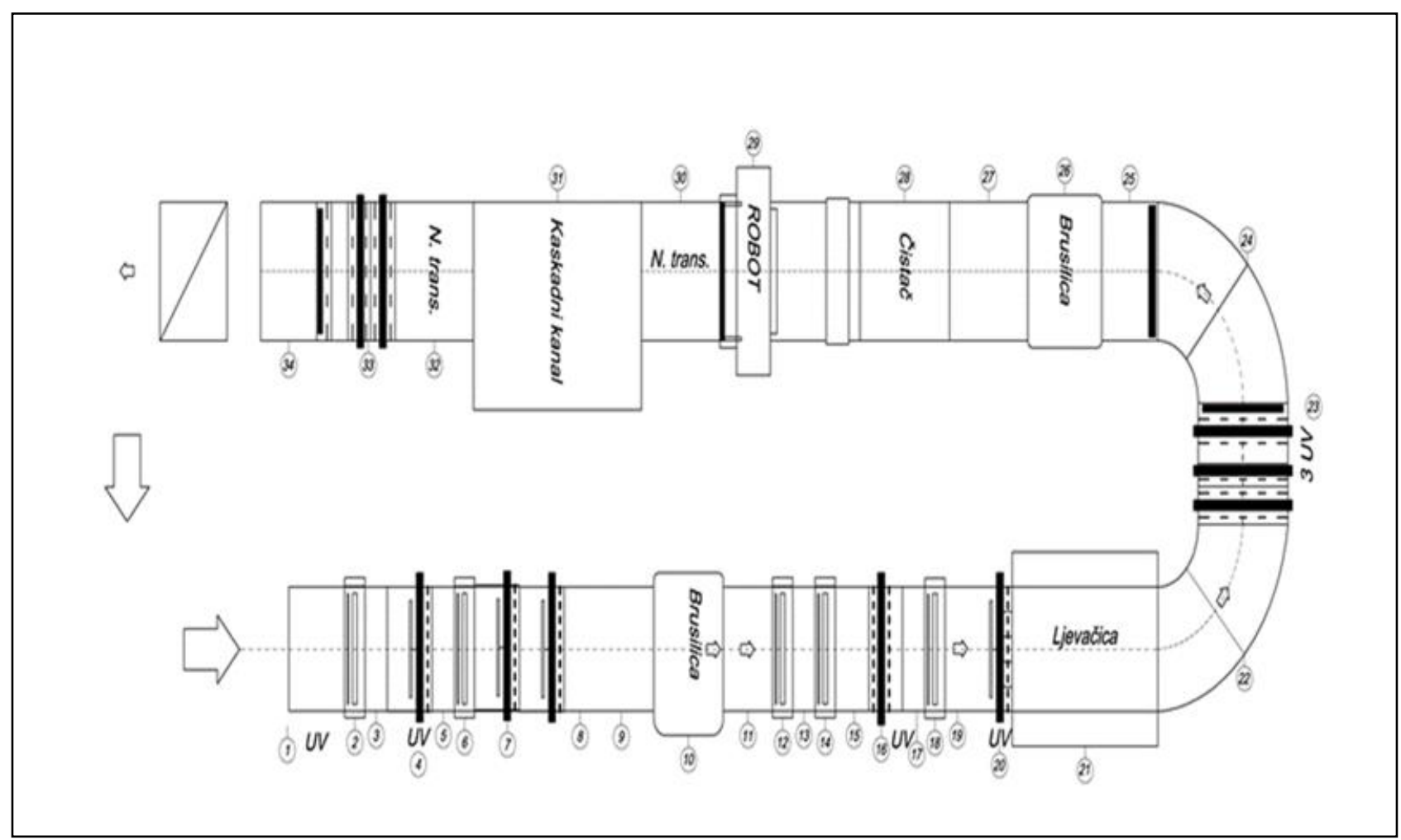

Fig. 1. Spraying line for wood panel elements processing with the electronic spraying. 
The procedure consists from wood panel which was previously processed with the use of grinder, which is then sent to internal transporter (poz.1), than the UV primer is being applied by using the roller (poz.2). Transport line (poz.3) than sends the wood panel in drying line which drys the wood panel with the help of UV lamp (poz.4), afterwards second UV primer is being applied with the manual roller (poz.6) than it drys wood panel once more with the use of two UV lamp (poz.7).

In order to apply the primer on the right side, grinding is done first (poz.9), than UV primer is being applied with roller (poz.11) or Bianco UV primer (poz.13). Primer than dries in oven with the use of UV lamp (poz.15), afterwards second UV primer is being applied with roller (poz.17) which than dries once again in over with one UV lamp (poz.19). With the use of pouring device, the primer is being applied (poz.20) which than dries with the use of three UV lamp. Using grinder tool (poz.25), all wood hairs are being removed and the cleaner (poz.27) helps to keep the wood surface as cleaner as possible without dust, which ensures the quality of primer. Once again, primer is being applied using automatic spray device (poz.28) and than it goes trough cascading channel (poz.30) all the way to oven where it dries using three UV lamp. At last, processed wood panel ends up on outside transport line (poz.33). The speed of spray line in $3,5 \mathrm{~m} / \mathrm{min}$.

\section{Manual spray line for wood element processing}

The procedure consists from a wood panel, which was previously processed with the help of grinder, which is than put send on movable shelf which has $360^{\circ}$ rotation and once again, the water primer is being manually applied. Than the wood panel is being send on to grating truss for drying the surface film. Drying process is being done on room temperature $210 \mathrm{C}$ and relative air humidity of $51 \%$.

After drying, wood panel is sent on grinding a primer which was previously applied, after grinding is done, wood panel is sent on to movable shelf and than, the second primer layer is being applied. Once again, wood panel is sent on to drying, after drying is completed, the wood panel is grinding with the use of grinding tool, surface is being manually cleaned, than wood panel is send once more on to movable shelf where the final water primer is being applied. After primer is being applied, wood panel than goes on to drying, with the use of grating truss. It takes $48 \mathrm{~h}$ in order to complete the drying of water primer.

In this paper work, viscosity tests are performed (conditional and absolute), content of dry material as well as volatile ingredients, quantity of applied liquid materials, the thickness of wood film and etc.

Conditional viscosity examination is being done according the FORDU-u JUS B.H8.021. Key characteristics of instruments are as follows: funnel volume $100 \pm 1$ with leakage opening $4 \mathrm{~mm}$ wide. Viscosity measurement is being performed on room temperature $21^{\circ} \mathrm{C}$ and relative air humidity around $51 \%$. 


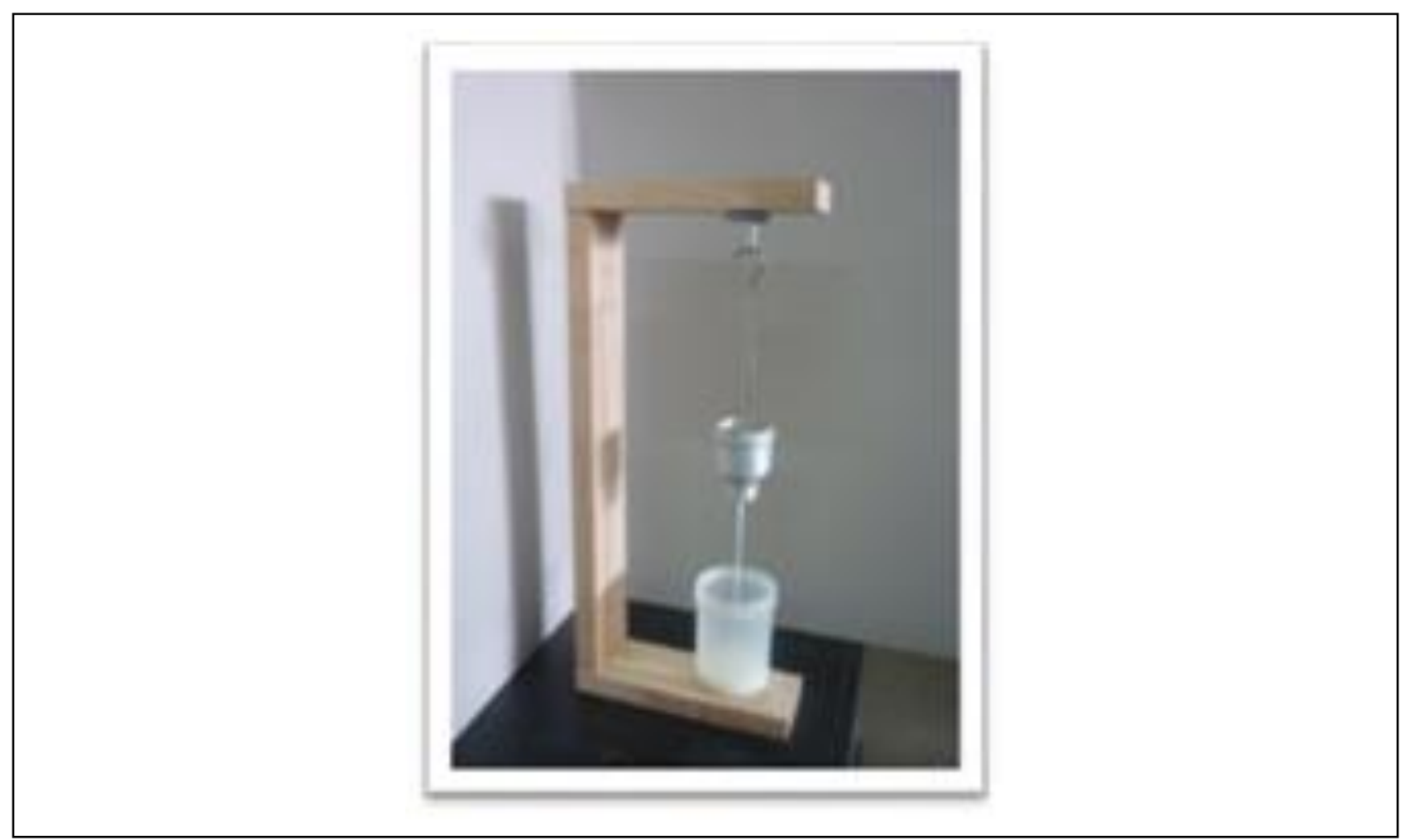

Fig. 2. Viscosity examination (Ford).

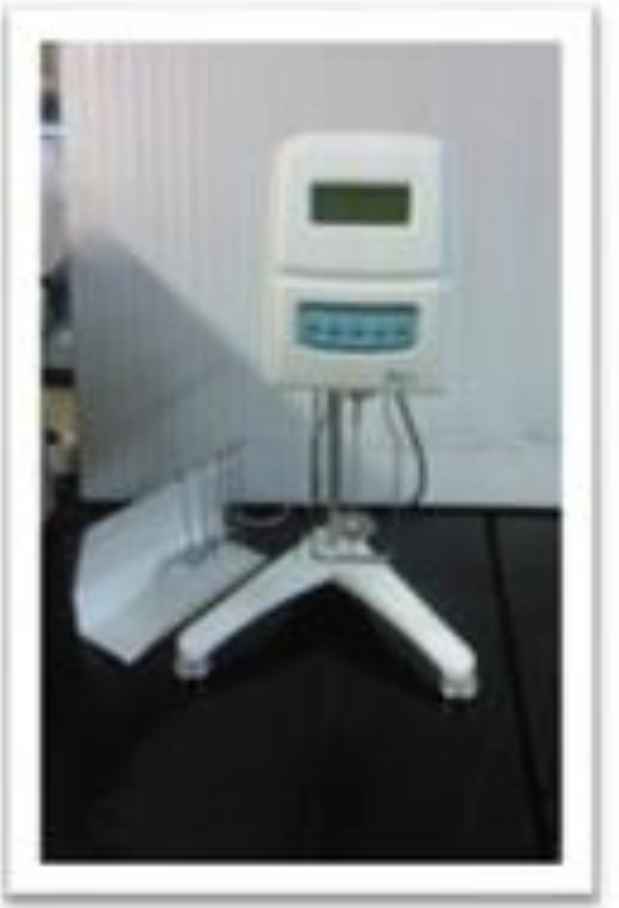

Fig. 3. Viscosity examination (Brookfield).

Before measurement can be done, device for viscosity must be calibrared. Horizontal viscometer is being closed on the top of opening with the help of finger, than it is filled with examined material all the way to the top, and with the help of glass plate excess material is being removed. Once the finger is removed from the top of opening, stopwatch is turned on wich measure time of leaked liquid to time of liquid 
stream interruption. Purpose of Brokfield method is to determine the viscosity rotation. Spindle rotation resistance is one of the many function of viscosity of the examined materials and it's being presented on scale. Content of dry material with the use of UV water and water primer, is determined by force drying in the lab oven. Examination is being performed using wood panel (oak) 100x100x0.18 [mm] and digital scale device (accuracy 0,1 g).

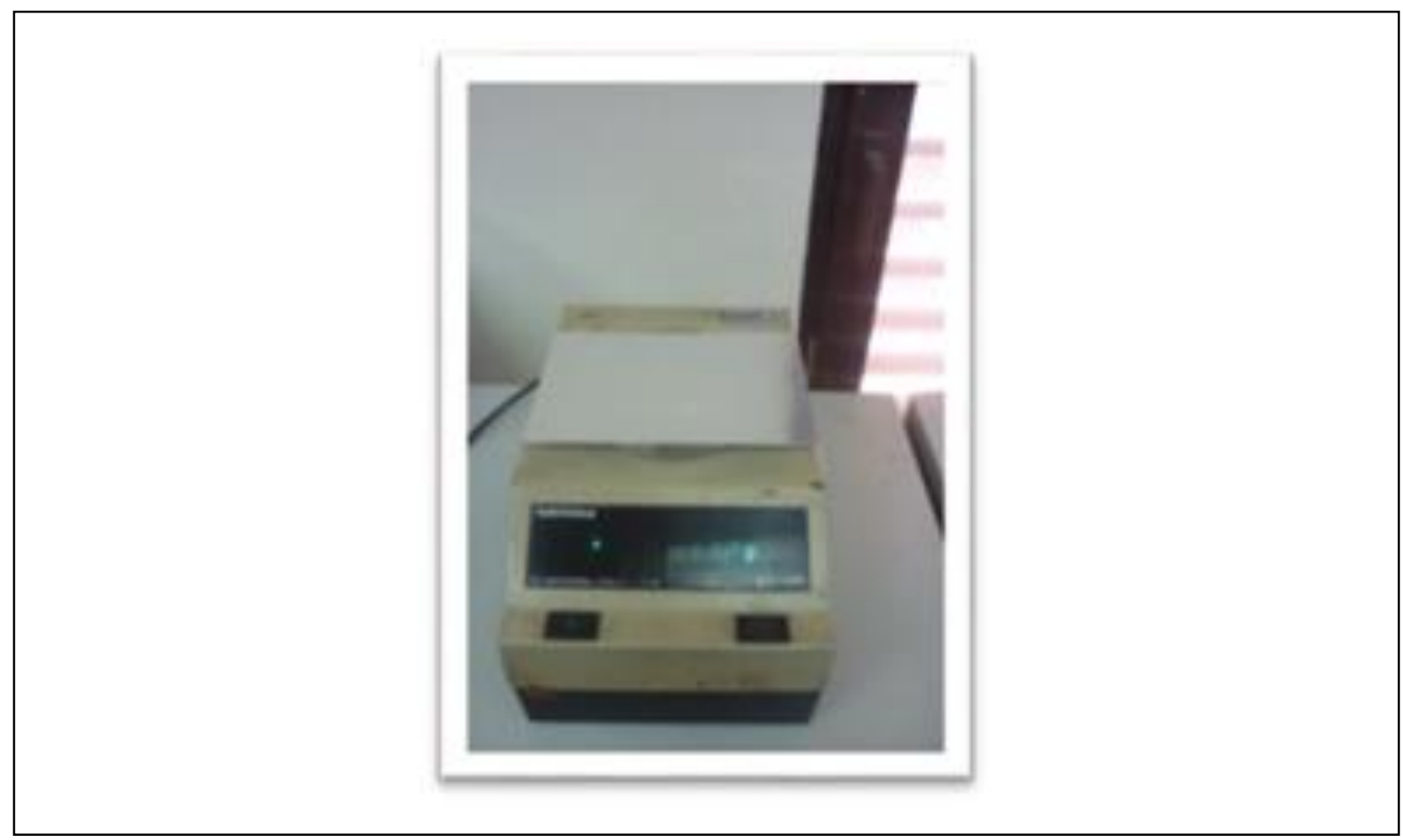

Fig. 4. Weight tube measurement without primer.

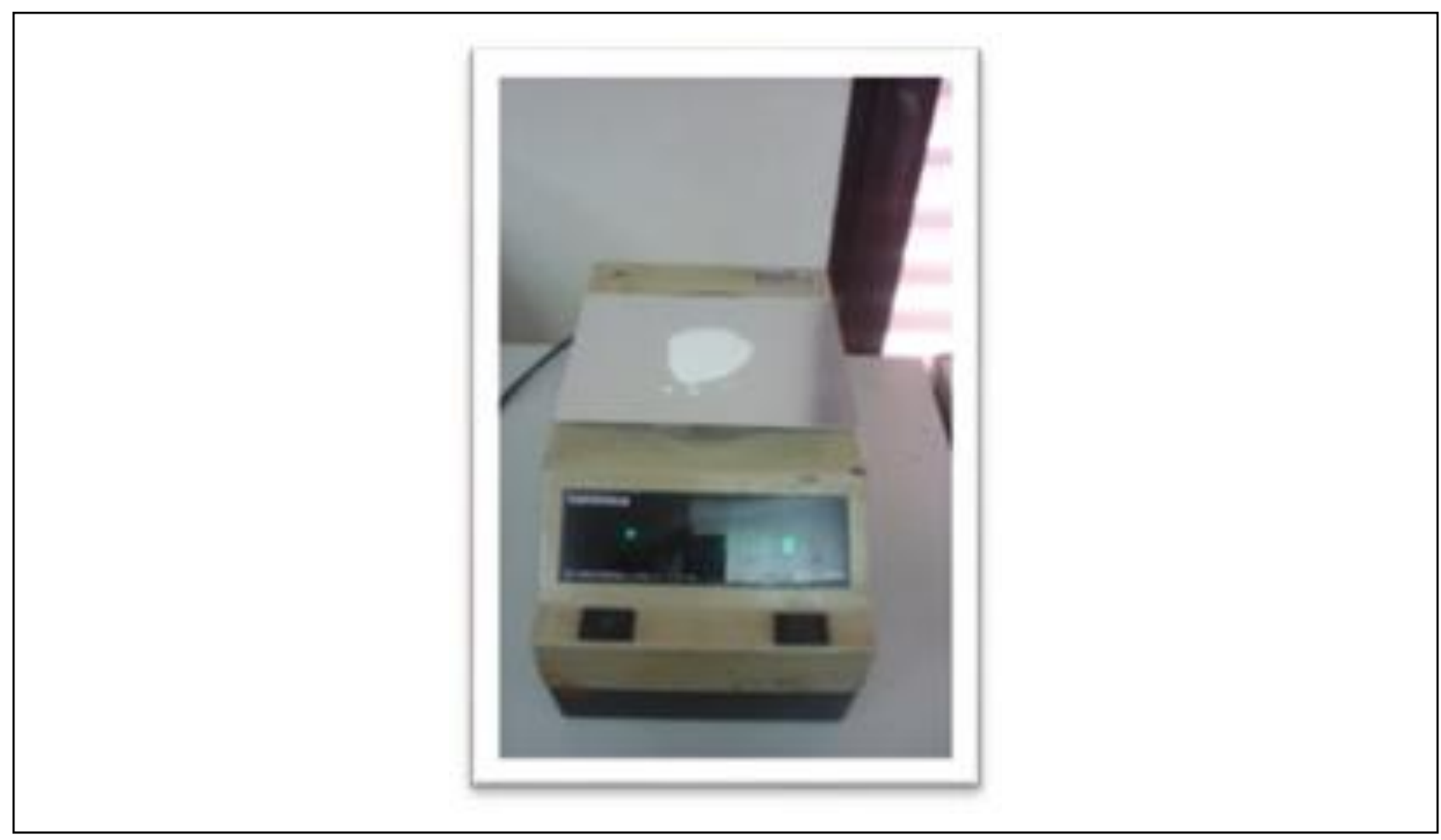

Fig. 5. Weight tube measurement with primer. 
Horman, I.; Azemovic, E. \& Pandzo, A.: CNC Technology in Wood Surface Proce...

Water primer is being applied manually on processed surface and trogh automatic airless dispersion. During primer appliying, low environment temperature is $21^{\circ} \mathrm{C}$ and relative air humidity is around 51\&. In this case, water primer is being applied on wood (oak) surface with the dimension 100x100x0,18 mm, aftertwards examinitaion of quantity of liquid material is being performed.

During measurement, six test tubes are being used. Before primer could be applied, the tape is glued on the middle of the tubes. Tape width used in this work was 5-7 mm due to limitation of spaces between foot of comparator. The primer is than applied on tube, than it dries in room condition. After drying is completed, tapes are being removed from the middle, and using the comparator device, the width of dry film is measured. Comparator of Erichson manufacturer is being placed on several tube places.

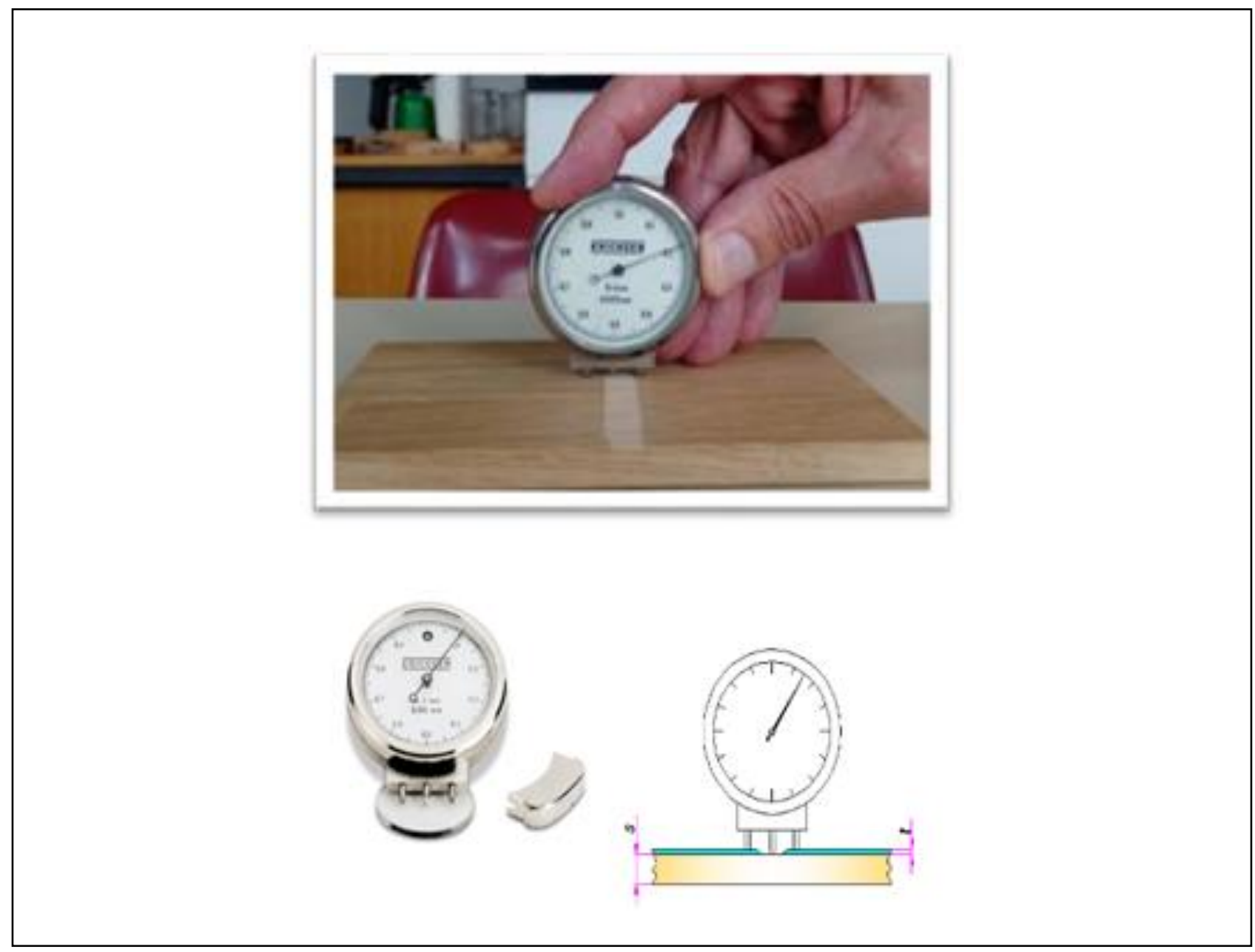

Fig. 6. Mechanical measurement of width of the dry film.

\section{Results and discussion}

The following table demonstrates the results of leakage time of water primer and leakage time of UV primer. 


\begin{tabular}{|c|c|c|c|c|c|}
\hline \multirow[b]{2}{*}{ Type of varnish } & \multicolumn{3}{|c|}{ FORDU -u JUS B.H8.021. } & \multirow[b]{2}{*}{ Volume [ml] } & \multirow[b]{2}{*}{ Time [sec] } \\
\hline & $4[\mathrm{~mm}]$ & [6 mm] & [8 mm] & & \\
\hline Water-based varnish & $4 \mathrm{~mm}$ & - & - & 100 & 240" \\
\hline
\end{tabular}

Tab. 1. Experiment results according to Ford for conditional viscosity.

\begin{tabular}{|c|c|c|c|c|c|}
\hline \multirow{2}{*}{ Type of varnish } & \multicolumn{3}{|c|}{ FORDU -u JUS B.H8.021. } & \multirow{2}{*}{ Volume [ml] } & Time [sec] \\
\cline { 2 - 4 } & $\mathbf{4}[\mathbf{m m}]$ & {$[\mathbf{6 ~ m m}]$} & {$[\mathbf{~ m m}]$} & 100 & $\mathbf{1 1 7}$ \\
\hline $\begin{array}{c}\text { UV water-based } \\
\text { varnish }\end{array}$ & $4 \mathrm{~mm}$ & - & - & & \\
\hline
\end{tabular}

Tab. 2. Experiment results according to Ford for conditional viscosity.

\begin{tabular}{|l|c|}
\hline \multicolumn{1}{|c|}{ Type of varnish } & Viscosity [mPa·s] \\
\hline \hline Water-based varnish & 750 \\
\hline UV water-based varnish & 1230 \\
\hline
\end{tabular}

Tab. 3. Experiment result according to Brookfield for absolute viscosity.

\begin{tabular}{|c|c|c|c|c|}
\hline Type of varnish & $\mathbf{m}_{\mathbf{1}}[\mathbf{m m}]$ & $\mathbf{m}_{2}[\mathbf{m m}]$ & Si [\%] & Sm [\%] \\
\hline $\begin{array}{c}\text { Water-based } \\
\text { varnish }\end{array}$ & 0,67 & 1,76 & 61,93 & $\mathbf{3 8 , 0 7}$ \\
\hline
\end{tabular}

\begin{tabular}{|c|c|c|c|c|}
\hline Type of varnish & $\mathbf{m} \mathbf{1}[\mathbf{m m}]$ & $\mathbf{m}_{2}[\mathbf{m m}]$ & Si [\%] & Sm [\%] \\
\hline $\begin{array}{c}\text { Water-based } \\
\text { varnish }\end{array}$ & 0,74 & 1,86 & 60,21 & $\mathbf{3 9 , 7 8}$ \\
\hline
\end{tabular}

Tab. 4. Experiment results with dry material content.

Percentage of dry matter content of UV water primer is much grater than percentage of dry material of water primer. Percentage of volatile matter content of water primer is greater than percentatge of UV water primer volatile matter content.

\begin{tabular}{|c|c|c|c|c|}
\hline \multirow{2}{*}{ Type of varnish } & $\mathbf{m}_{\mathbf{2}}[\boldsymbol{g}]$ & $\mathbf{m} \mathbf{1}[\boldsymbol{g}]$ & $\mathbf{A}\left[\boldsymbol{m}^{\mathbf{2}}\right]$ & $\mathbf{Q}\left[\frac{g}{m^{2}}\right]$ \\
\hline \multirow{2}{*}{ Water-based varnish } & 123,5 & 122,3 & 0,01 & $\mathbf{1 2 0 , 0}$ \\
\cline { 2 - 5 } & 123 & 122,3 & 0,01 & $\mathbf{7 0 , 0}$ \\
\hline
\end{tabular}

\begin{tabular}{|c|c|c|c|c|}
\hline Type of varnish & $\mathbf{m}_{2}[\boldsymbol{g}]$ & $\mathbf{m}_{\mathbf{1}}[\boldsymbol{g}]$ & $\mathbf{A}\left[\mathbf{m}^{\mathbf{2}}\right]$ & $\mathbf{Q}\left[\frac{\boldsymbol{g}}{m^{2}}\right]$ \\
\hline \hline $\begin{array}{c}\text { UV-Water-based } \\
\text { varnish }\end{array}$ & 123,3 & 122,3 & 0,01 & $\mathbf{1 0 0 , 0}$ \\
\cline { 2 - 5 } & 122,9 & 122,3 & 0,01 & $\mathbf{6 0 , 0}$ \\
\hline
\end{tabular}

Tab. 5. Experiment results with material content quantity. 
Horman, I.; Azemovic, E. \& Pandzo, A.: CNC Technology in Wood Surface Proce...

Quantity of applied liquid material on to wooden surface using manual method is greater than liquid material quantity applied on to wooden surface using autmatic spray device.

\begin{tabular}{|c|l|c|}
\hline \multirow{2}{*}{ Type of varnish } & Application method & Film thickness $[\boldsymbol{\mu m}]$ \\
\hline \multirow{3}{*}{ Water-based varnish } & Manual spraying & $\mathbf{6 9}$ \\
\cline { 2 - 3 } & Manual spraying & $\mathbf{4 6}$ \\
\hline \multirow{3}{*}{ UV-Water-based varnish } & Electronic spraying & $\mathbf{5 9}$ \\
\cline { 2 - 3 } & Electronic spraying & $\mathbf{3 4}$ \\
\hline
\end{tabular}

Tab. 6. Thickness of dry water primer and UV primer film.

Thickness of dry film is less than the thickness of UV water primer which was applied using electronic spray device, than the one applied manually usig roller and water primer

\section{Conclusion}

Product quality is the key goal of every modern and organized production. With the increase of automation process using $\mathrm{CNC}$ machine, precision and product quality has also increased. CNC production has decreased the number of scraps, increase the speed and flexibility of production, while it has decreased the number of employee. On the other hands, the production cost has been reduced. So to say, advantage in automated primer spraying, are as follows:

- Increased quality. Automated spray device can provide correct regulation and spray gun movement for even application of paint.

- Material savings It can be achieved with even primer application as well as right rhythm of spray gun activating and deactivating;

- Energy cost. It is achieved because automated cell for primer application doesn't require any complex heating or ventilation system ;

- Increased productivity. It is achieved by decreasing the participation of human labor and it's cost;

Results of this paper work have showned that by using CNC technology, we have justified investment for highquality wood panel production.

\section{References}

Horman I., Vukas N., Azemović E., CNC tehnologije u finalnoj obradi drveta, Mašinski fakultet, Sarajevo 2014.g.

Jaić M., Živanović R., Površinska obrada drveta, Beograd 2000.g.

Alić O., Površinska obrada drveta, Mašinski fakultet, Sarajevo, 1997.g.

Smajlović F., Magistarski rad, Ultraviolentno zračenje u tehnologiji površinske obrade drveta, Sarajevo 2013. 